\title{
Adsorption of Zirconium Ions by X-Type Zeolite
}

\author{
Hanna Vasylyeva ${ }^{1, *}$ (D), Ivan Mironyuk ${ }^{2}$ (D), Mykola Strilchuk ${ }^{3}$ (D), Volodymyr Tryshyn ${ }^{3,4}$, Olexander \\ Gaidar $^{3,4}$ (D), Oleksander Vasyliev 5 (D)
}

1 Department of Theoretical physics, Uzhgorod National University, 14 Universytetska Str., 88000, Uzhgorod, Ukraine; h.v.vasylyeva@hotmail.com (H.V.);

2 Department of Chemistry, Vasyl Stefanyk Precarpathian National University, 57 Shevchenko Str., 76018 Ivano Frankivsk, Ukraine;_myrif555@gmail.com (I.M.);

3 Institute for Nuclear Research of NAS Ukraine, Laboratory of Nuclear Forensics, Nauky Avenue 47, Kyiv, Ukraine; myst@kinr.kiev.ua (M.S.);

4 Institute for Nuclear Research of NAS Ukraine, CEPAE, Nauky Avenue 47, Kyiv, Ukraine; vtryshyn@ kinr.kiev.ua (V.T.);

5 Institute of Electron Physics_of NAS Ukraine, 21 Universytetska Str., 88017, Uzhgorod, Ukraine; nucleargoga @ gmail.com (O.V.);

* Correspondence: h.v.vasylyeva@hotmail.com (H.V.);

Scopus Author ID 65061599572

Received: 8.01.2021; Revised: 2.02.2021; Accepted: 5.02.2021; Published: 13.02.2021

Abstract: Dependence of zirconium adsorption value on agitation time, solution acidity, equilibrium concentrations of zirconium cations, and zeolite NaX particle size was investigated. The two most common adsorption theories Langmuir and Freundlich, were used to analyzing equilibrium adsorption data. Nonlinear approximation shows that the Freundlich adsorption theory provides higher $\mathrm{R}^{2}$ and lower $\chi^{2}$ for zirconium adsorption by $\mathrm{NaX}$ than the Langmuir adsorption theory. Experimental maximum adsorption values of $\mathrm{NaX}$ toward zirconium and strontium cations are $75 \mathrm{mg} \cdot \mathrm{g}^{-1}$ and 156 $\mathrm{mg} \cdot \mathrm{g}^{-1}$, respectively. The desorption studies of zirconium ions from the surface of $\mathrm{NaX}$ by $1 \%$ oxalic acid and $10 \% \mathrm{HNO}_{3}$ were performed. Degradation of the adsorbent in nitric acid was studied in a batch mode. The recovered suspended particles filter cake was investigated by X-ray fluorescence analysis. Alumina oxide $\left(\mathrm{Al}_{2} \mathrm{O}_{3}\right)$ fraction decreases, and $\mathrm{MgO}$ is completely washed out from the adsorbent matrix in concentrated $\mathrm{HNO}_{3}$.

Keywords: zirconium; zeolite; adsorption; dissolution; strontium.

(C) 2021 by the authors. This article is an open-access article distributed under the terms and conditions of the Creative Commons Attribution (CC BY) license (https://creativecommons.org/licenses/by/4.0/).

\section{Introduction}

Radioactive materials and radionuclides are widely used in science, education, medicine, atomic energy, etc. Radioactive contamination can be a result not only of NPP facility but also of nuclear weapons testing. Over the last 50 years, several inorganic adsorption materials are used to purify water solutions from radionuclides, for example, from ${ }^{90} \mathrm{Sr}$ or ${ }^{60} \mathrm{Co}$ [1-9]. Zeolites are crystalline hydrated aluminosilicates. Synthetic and natural aluminosilicates occupy an essential place among other silicon-based adsorbents such as titanium silicate [10], nano-sized stannic silicomolybdate [11], or fumed silica [12, 13], which are offered for adsorption of heavy metals cations and radionuclides from aqueous solutions. The unique structure of zeolites makes them attractive for various practical applications, including gas and vapor separations, membrane reactors, chemically selective adsorption, and slow-release fertilizers in agriculture [14]. ${ }^{90} \mathrm{Sr}$ adsorption onto modified zeolites over the past 10 years is described in publication [4]. The structure of zeolites can be modified with heavy metal cations, such as $\mathrm{Cu}^{2+}$, to enhance the adsorption and catalytic properties [15]. Many natural, synthetic, 
and modified zeolites were proposed for the adsorption of heavy metal cations such as $\mathrm{Pb}^{2+}$, $\mathrm{Cd}^{2+}, \mathrm{Cu}^{2+}, \mathrm{Mn}^{2+}, \mathrm{Ni}^{2+}, \mathrm{Pb}^{2+}, \mathrm{Zn}^{2+}$, and $\mathrm{NH}_{4}^{+}[1-5,16-22]$. The high adsorption capacity of zeolites, relative to strontium cations, and high radiation resistance, have led to the use of zeolite $\mathrm{NaX}$ as a carrier for ${ }^{90} \mathrm{Sr}[1]$.

On the other hand, among the many scientific papers on zeolites, few works are devoted to the adsorption of zirconium ions by zeolites. Zirconium is a well-known radiation resistance metal dopant because of its small neutron capture cross-section. It is widely used in alloys from which the core of nuclear reactor housings are made. Zirconium has several isotopes. Some of them are being used for medical purposes; for example, ${ }^{89} \mathrm{Zr}$ is used as a positron emitter in PET diagnostic. Isotopes of ${ }^{92-95} \mathrm{Zr}$ can be produced as fission radionuclides during uranium nuclear fission. Therefore, isotopes of ${ }^{92-95} \mathrm{Zr}$, along with ${ }^{90} \mathrm{Sr}$, can be found in radioactive waste. Ion exchange resins DOWEX 50WX4 is usually proposed for the adsorption of zirconium ions, as well as compounds based on silicon or biowaste rice bran. Extraction, chelation, or adsorption of zirconium ions by hydroxamate resin is offered to isolate zirconium for medical purposes [23-26].

Our research reviews zirconium adsorption by zeolite $\mathrm{NaX}$ compares obtained results versus strontium adsorption in similar conditions and studies zirconium desorption and $\mathrm{NaX}$ degradation in acid medium.

\section{Materials and Methods}

In the present work, commercial synthetic $\mathrm{NaX}$ zeolite was used. Zeolite $\mathrm{NaX}$ relates to the faujasite topology (FAU). The main source material for $\mathrm{NaX}$ is kaolin [27-30]. $\mathrm{NaX}$ lattices have a network of pores with a diameter of nearly 7,4 -8 $\AA$. In $\mathrm{NaX}$, ' $\mathrm{X}$ ' means that $\mathrm{Si} / \mathrm{Al}$ ratio in zeolite equals 1-1,4. According to [31], the zeolite $\mathrm{Si} / \mathrm{Al}$ ratio plays a universal role in the acid medium's zeolite's stability. All chemical compounds, including $\mathrm{ZrOCl}_{2}, \mathrm{NaX}$, $\mathrm{NH}_{4} \mathrm{OH}, \mathrm{HNO}_{3}, \mathrm{SrCl}_{2} \cdot 6 \mathrm{H}_{2} \mathrm{O}$, and oxalic acid $\left(\mathrm{H}_{2} \mathrm{C}_{2} \mathrm{O}_{4} \times 2 \mathrm{H}_{2} \mathrm{O}\right)$, were of reagent grade and used without further purification. Distilled and deionized water was obtained using a three-stage water purification system.

\subsection{XRF analysis.}

The chemical composition of zeolite $\mathrm{NaX}$ and $\mathrm{Si} / \mathrm{Al}$ ratio were confirmed by fluorescent X-ray analysis using S2Ranger (C2010 Bruker AXS (Karlshrue, Germany). The $\mathrm{XRF}$ analysis was provided with voltage $50 \mathrm{kV}$; tube current $1000 \mu \mathrm{A}$; pressure $1000 \mathrm{mBar}$; filter $250 \mathrm{~mm} \mathrm{Cu}$. The spectrometer records a "number of count" $\mathrm{N}$ versus $2 \theta$, the position of the detector. This $2 \theta$ position can be converted in the wavelength $\lambda$ with the Bragg's low, end photon E's energy (the energy of photons and the wavelength of the radiation are linked by the Plank's constant). The content of corresponding elements, was determined by KA1 lines with energy of 1,041 keV (Na); 1,25keV ( Mg); 1,74keV (Si); 1,48 keV (Al); 3,69keV (Ca); 4,511 $\mathrm{keV}(\mathrm{Ti}) ; 14,166 \mathrm{keV}(\mathrm{Sr}) ; 15,6 \mathrm{keV}(\mathrm{Zr})$.

\subsection{Determination of the point of zero charges.}

The point of zero charges of the $\mathrm{NaX}$ surface was determined using the drift method. $100 \mathrm{mg}$ of $\mathrm{NaX}$ was added to $15 \mathrm{ml} 0,1 \mathrm{M} \mathrm{NaCl}$ solution and the ionic strength was kept constant in all experiments. The initial $\mathrm{pH}$ value was adjusted from 2,0 to 11,0 by adding $0,1 \mathrm{M}$ $\mathrm{HCl}$ or $\mathrm{KOH}$ solutions. The solutions were kept for 24 hours. The final $\mathrm{pH}$ value was measured 
using $\mathrm{pH}$ meter with a glass electrode. The point of zero charges was considered at a straightline $\mathrm{pH}_{\text {final }}=\mathrm{pH}$ initial cross with the experimental curve $\mathrm{pH}_{\text {final }}$ versus $\mathrm{pH}_{\text {initial. }}$ Point of zero charge of $\mathrm{NaX}$ surface has $\mathrm{pH}=11,5$.

\subsection{Adsorption and desorption sudies.}

Adsorption investigations were performed in a batch mode with the liquid: solid (L: S) phase ratio equal to 50 ( $\left.m_{\mathrm{ads}}=0,1 \mathrm{~g} ; V_{\mathrm{sol}}=5 \mathrm{ml}\right)$. To investigate desorption efficiency, the adsorption study was performed at standard conditions. After adsorption, the samples of $\mathrm{NaX}$ were washed with deionized distilled water. Then it was dried at room temperature. For the desorption study, a given mass (approximately $0,1 \mathrm{~g}$ ) of $\mathrm{NaX}$ was washed in $10 \mathrm{ml}$ of various desorbing agents. This study's desorbing agents included $10 \% \mathrm{HNO}_{3}$, concentrated $\mathrm{HNO}_{3}$, and $1 \%$ oxalic acid.

The initial and residual concentration of stable isotopes of zirconium was determined using direct complexometric titration in a strong acid medium with Xylenol Orange as an indicator. XRF analysis of zeolite samples before and after adsorption was performed, as well. The amounts of adsorbed zirconium ions were calculated using equation (1) according to [8, 32-35]:

$$
q_{e}=\frac{\left[\left(C_{o}-C_{e}\right) V\right]}{m}
$$

Where $\mathrm{q}_{\mathrm{e}}-$ is the amount of zirconium uptake, $\mathrm{mg} / \mathrm{g} ; \mathrm{C}_{\mathrm{o}}$ and $\mathrm{C}_{\mathrm{e}}-$ are initial and residual concentrations of zirconium, $\mathrm{mg}$; $\mathrm{V}$ - is solution volume, $\mathrm{L}$; and $\mathrm{m}$ - is mass adsorbent, $\mathrm{g}$.

Experimental data of adsorption kinetics were analyzed using models based on pseudofirst and pseudo-second-order equations, Elovich chemisorption kinetic model, and the WeberMorris intra-particle diffusion kinetic model. Corresponding equations (2-5) are given in Table 1 .

Table 1. Linear analytical equations of kinetic models (2)-(5).

\begin{tabular}{l|l} 
Kinetic model & Linear equation \\
\hline Elovih & $q_{t}=\frac{1}{b} \ln (a b)+\frac{1}{b} \ln (t)(2)$ \\
\hline Diffusion & $q_{t}=\operatorname{Dipd} \times t^{1 / 2}+k_{0}(3)$ \\
\hline Pseudo - first order & $\log \left(q_{0}-q_{t}\right)=\log q_{0}-k 1 t / 2.303(4)$ \\
\hline Pseudo-second order & $\frac{t}{q t}=1 / k 2 q_{0}^{2}+t / q_{o}(5)$
\end{tabular}

$\mathrm{q}_{\mathrm{o}}$ and $\mathrm{q}_{\mathrm{t}}(\mathrm{mg} / \mathrm{g})$ - adsorption capacity at equilibrium and time $\mathrm{t}$, respectively; $\mathrm{k}_{1}\left(\mathrm{~min}^{-1}\right), \mathrm{k}_{2}\left(\mathrm{~g} \cdot \mathrm{mg}^{-1} \mathrm{~min}^{-1}\right)$ rate coefficients of pseudo-first order equation and pseudo-second order equation. $\mathrm{D}_{\mathrm{ipd}}\left(\mathrm{mg} / \mathrm{g} \mathrm{min}{ }^{0,5}\right)-$ coefficient of intra-particle diffusion; $\beta$ (mg/g)- desorption constant, $\alpha$ (mg/g min) - rate coefficients of Elovich equation.

The equilibrium adsorption studies were performed under agitation times not less than 120 minutes. Nonlinear approximation of the experimental results was carried out by the Langmuir and Freundlich theories using the "Solver add-in" application to Microsoft Excel office program, according to $[34,35]$. The equations for both theories are given below:

$$
\begin{gathered}
q_{e}=\frac{A_{\infty} K C_{e}}{1+K C_{e}} \\
q_{e}=K_{f} \times C_{e}^{n}
\end{gathered}
$$

where, $\mathrm{A}_{\infty}$ - maximal adsorption value, which corresponds of fill in the whole adsorption centers, $\mathrm{mg} / \mathrm{g} ; \mathrm{K}_{\mathrm{L}}$ - Langmuir equation's constant, L/mg; $\mathrm{C}_{\mathrm{e}}-$ adsorbate equilibrium concentration, $\mathrm{mg} / \mathrm{L} ; \mathrm{q}_{\mathrm{e}}-$ the amount of adsorbate uptake at equilibrium, $\mathrm{mg} / \mathrm{g} ; \mathrm{K} f$ - Freundlich constant, $\frac{m g / g}{\left(\frac{m g}{L}\right) n} ; \mathrm{n}$ - Freundlich intencity parameter. 
Arithmetic mean and error of arithmetic mean were calculated using program [36], with the confidence level of $99 \%$. Values of $\mathrm{R}^{2}$ and $\chi^{2}$ were calculated by equations (8) and (9).

$$
\begin{gathered}
R^{2}=1-\frac{\sum\left(q_{e, \text { exp }},-q_{e, \text { calc }}\right)^{2}}{\sum\left(q_{e, \text { exp }}-q_{e, \text { mean }}\right)^{2}} \\
\chi^{2}=\sum \frac{\left(q_{e, \text { exp }}-q_{e, \text { calc }}\right)^{2}}{q_{e, \text { calc }}}
\end{gathered}
$$

The effect of solution acidity on adsorption processes was investigated using a certain amount of $\mathrm{HNO}_{3}$ or $\mathrm{NH}_{4} \mathrm{OH}$. The acidity of solutions was controlled by the $\mathrm{pH}$-meter "Belarus' 2003".

\section{Results and Discussion}

\subsection{Dependence of zirconium ion adsorption on interaction time and the equilibrium} concentration of zirconium ions in a neutral medium.

It has been shown that adsorption values increase with the increased duration of interactions. Equilibrium establishes after 100 minutes of contact between the zeolites surface and zirconium ions (Figure 1). The experimental data of zirconium adsorption by $\mathrm{NaX}$ fits well in the Lagergren pseudo-second-order kinetic model $\left(\mathrm{R}^{2}=0,999\right)$ and the Elovich kinetic model $\left(\mathrm{R}^{2}=0,898\right)$. If the principal adsorption mechanism is chemical interaction, the $\mathrm{q}_{\mathrm{e}}=\mathrm{f}(\operatorname{lnt}) \mathrm{plot}$ is a straight line, whose slope and intercept determine rate coefficient $\alpha(\mathrm{mg} / \mathrm{g} \mathrm{min})$ and desorption constant $\beta(\mathrm{mg} / \mathrm{g})$ in Elovich kinetic model. Application of the pseudo-first kinetic model or intra-particle diffusion model gives lower correlation coefficients $\left(R^{2}=0,800\right.$; and $\mathrm{R}^{2}=0,669$ respectively (Table 2 ).

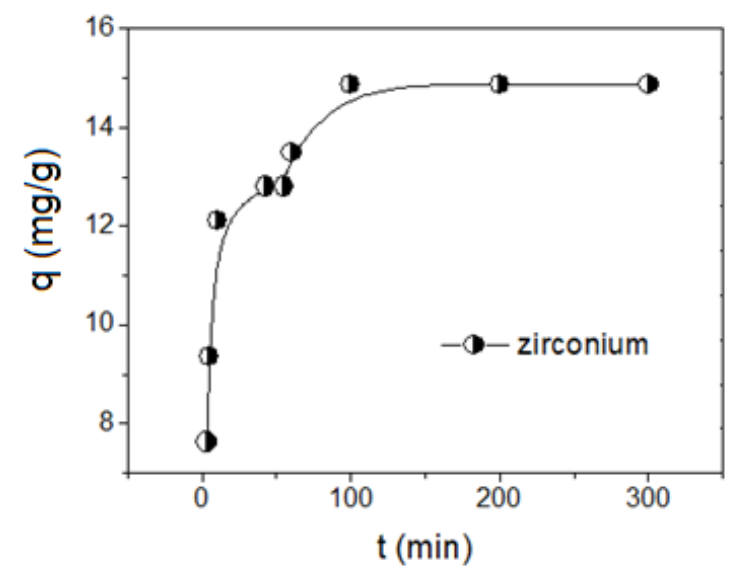

Figure.1. The effect of time interaction on zirconium ions adsorption by $\mathrm{NaX}(\mathrm{L}: \mathrm{S}=50, \mathrm{pH}=7)$. The initial concentration of zirconium ions is $0,005 \mathrm{M}$.

Table 2. Applying kinetic models to experimental results of zirconium adsorption by NaX.

\begin{tabular}{c|c|c|c} 
Kinetic model & Adsorption equation & Relate coefficients & $\mathbf{R}^{\mathbf{2}}$ \\
\hline Diffusion & $q_{t}=0,41 t^{0,5}+9,3$ & $\mathrm{D}_{i p d}=0,41$ & 0,6689 \\
\hline Elovich & $q_{t}=1,5 \ln t+7,1$ & $\begin{array}{c}\beta=0,66 \\
\alpha=16,44\end{array}$ & 0,898 \\
\hline Pseudo-first order & $\log \left(q_{0}-q_{t}\right)=-0,0091 t+0,75$ & $\mathrm{k}_{1}=0,009$ & 0,8003 \\
\hline Pseudo-second order & $\frac{t}{q_{t}}=0,066 t+0,32$ & $\mathrm{k}_{2}=0,066$ & 0,9992
\end{tabular}

The influence of zirconium equilibrium concentrations on its adsorption values by $\mathrm{NaX}$ is shown in Figure 2. Zirconium adsorption by zeolite NaX grows in the range of zirconium equilibrium concentrations $27-3000 \mathrm{mg} / \mathrm{L}$. This process is well described by the Freundlich adsorption theory. 

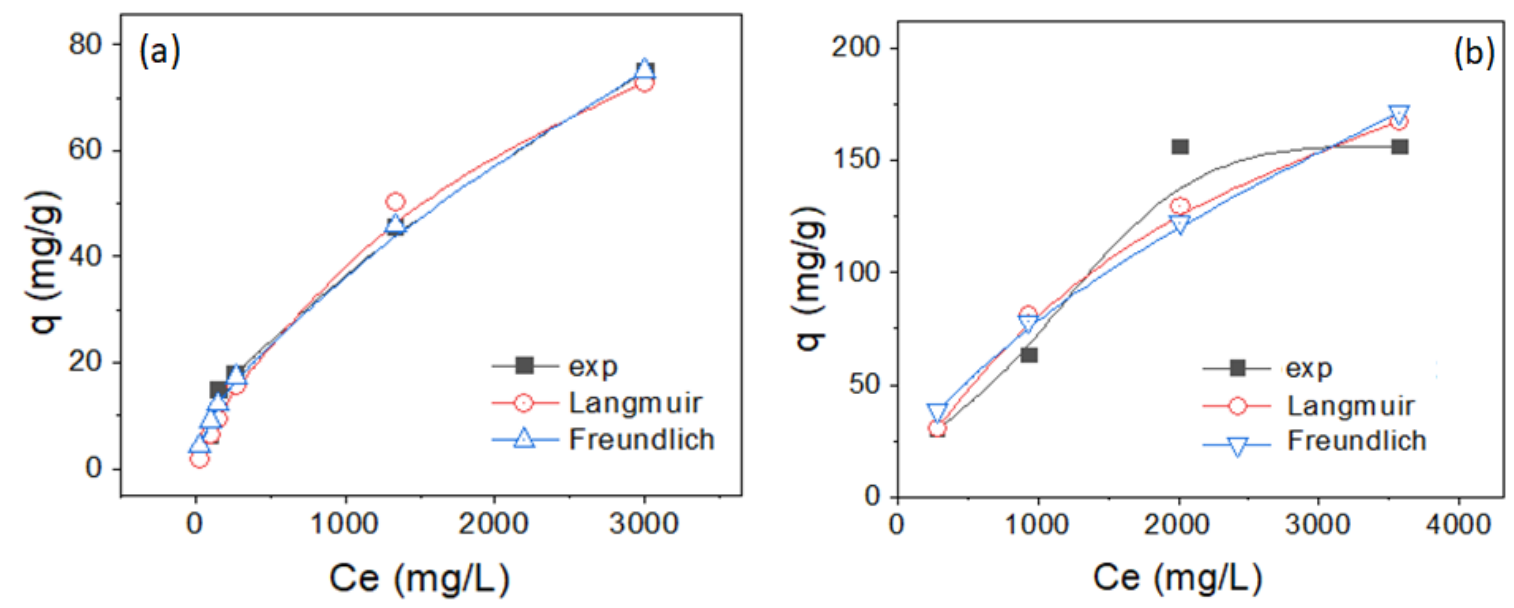

Figure.2. (a) Isotherm of adsorption of zirconium ions by $\mathrm{NaX}$ ( $\mathrm{L}: \mathrm{S}=50, \mathrm{pH}=7$ ), a nonlinear approximation of experimental adsorption isotherm by Langmuir and Freundlich adsorption theories; (b) Isotherm of strontium adsorption by $\mathrm{NaX}$ from aqueous solution in neutral medium.

Table 3. Nonlinear approximation of equilibrium adsorptions of $\mathrm{Zr}^{4+}$ and $\mathrm{Sr}^{2+}$ by $\mathrm{NaX}$.

\begin{tabular}{l|l|l|l|l} 
Cation & Theories & Parameters of equation & $\mathbf{R}^{2}$ & $\chi^{2}$ \\
\hline $\begin{array}{l}\mathrm{Zr}^{4+} \\
\begin{array}{l}\text { exp }=75 \\
\mathrm{mg} / \mathrm{g}\end{array}\end{array}$ & Langmuir & $\begin{array}{l}A_{\max }=113,96 \\
K_{L}=0,000593\end{array}$ & 0,9839 & 4,964 \\
\cline { 2 - 5 } & Freundlich & $\begin{array}{l}\mathrm{n}=0,611 \\
K_{f}=0,561\end{array}$ & 0,9947 & 2,114 \\
\hline $\begin{array}{l}\mathrm{Sr}^{2+} \\
\begin{array}{l}\mathrm{exp}=156 \\
\mathrm{mg} / \mathrm{g}\end{array}\end{array}$ & Langmuir & $\begin{array}{l}A_{\max }=269,3 \\
K_{L}=0,000461\end{array}$ & 0,9077 & 10,19 \\
\cline { 2 - 5 } & Freundlich & $\begin{array}{l}\mathrm{n}=0,588 \\
K_{f}=1,39\end{array}$ & 0,8669 & 15,38
\end{tabular}

Applying the Freundlich adsorption theory to the experimental results of zirconium adsorption by $\mathrm{NaX}$ gives higher $\mathrm{R}^{2}$ values than the Langmuir adsorption theory. $\mathrm{R}^{2}$ close to a unit $(0,9947)$ indicates an adequate description of the zirconium adsorption onto $\mathrm{NaX}$ by the Freundlich adsorption theory (which is used to describe the experimental data of adsorption on heterogeneous surface, i.e., a surface with different types of adsorption centers [34]). This conclusion confirms a low chi-squared value $\left(\chi^{2}=2,114\right)$ (Table 3$)$. Experimental results of strontium adsorption, in contrast, are well described by Langmuir adsorption theory, which indicates that strontium is involved in adsorption centers of essentially the same type.

\subsection{The effect of solution acidity and size of zeolite particles on zirconium ions adsorption.}

The dependence of the adsorption value of the zirconium ions by $\mathrm{NaX}$ from solution acidity is shown in Figure 3. Adsorption values of zirconium by zeolite grows with the pH increase. The error of arithmetic mean decreases with increasing $\mathrm{pH}$ value. This fact shows that zirconium ions' dominant adsorption occurs in a neutral medium, in the chemical states of $\mathrm{ZrO}^{2+}$ or $\mathrm{HZrO}_{2}^{+}[26]$. 


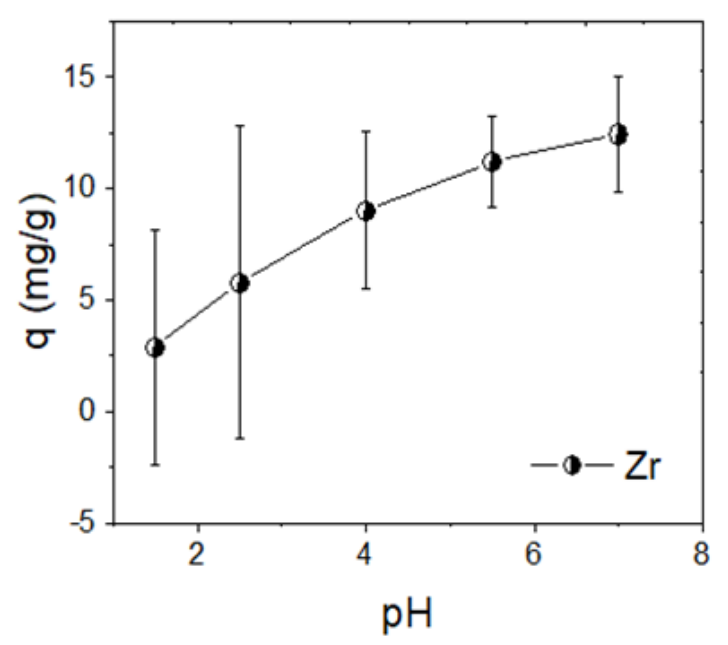

Figure 3. The dependence of the adsorption value of the zirconium ions by $\mathrm{NaX}$ from solution acidity (initial concentrations of zirconium ions were 0,001M. Error of arithmetic mean (percentage) of adsorption values calculated with a confidence level of $99 \%)$.

According to literature data, zirconium exists in the form of $\mathrm{ZrO}^{2+}$ in the range of $\mathrm{pH}$ values 2-7,5. Hydrated $\mathrm{Zr}(\mathrm{IV})$ exists as multiple monomeric and polynuclear oxy- and hydroxy-bridged species in solution at low pH due to its high charge and small radius [37]. Beyond $\mathrm{pH}=7,5 \mathrm{ZrO}_{2}$ precipitates in an insoluble form. Zirconium hydroxide does not interact with the surface of $\mathrm{NaX}$ because it has Lawis acid sites (accepted electrons) on the surface [38]. At the same time, $\mathrm{NaX}$ has acid sites of Brønsted acid sites (donated protons) and Lewis acid sites [30].

The dependence of adsorption values of zirconium ions on the size of zeolite particles is shown in Figure 4. Adsorption of zirconium ions is inversely proportional to the size of zeolite particles. Thus the maximum zirconium adsorption occurs where zeolite is in a powder form.

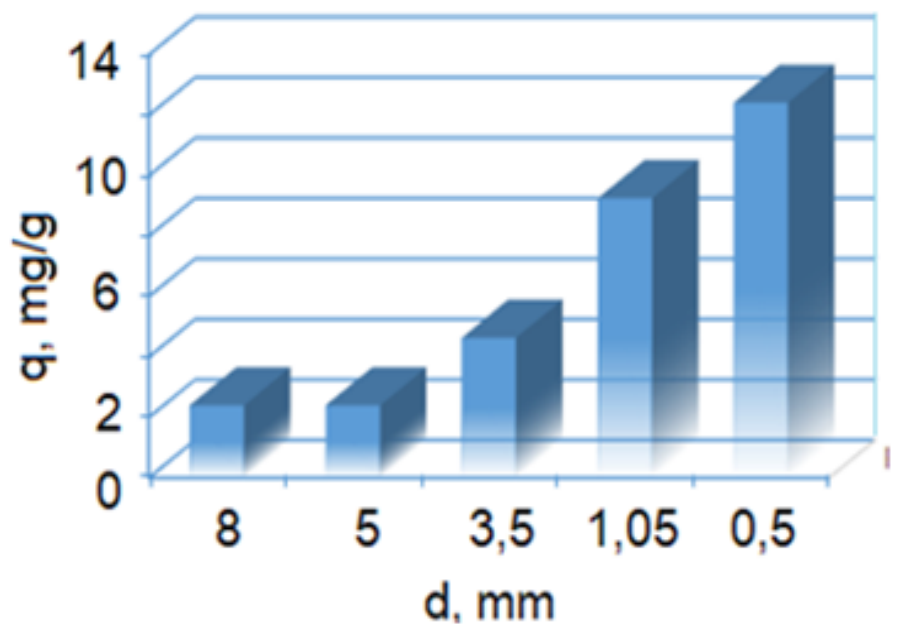

Figure 4. Dependence of zirconium adsorption values on particle size of $\mathrm{NaX}(\mathrm{mm})$, initial concentrations of zirconium ions is $0,001 \mathrm{M}, \mathrm{pH}=7$.

\subsection{Desorption of zirconium from zeolite surface. NaX dissolution in nitric acid.}

The fluorescent X-ray analysis confirmed the presence of adsorbed zirconium (or strontium) on the NaX surface (Figures 5, 6, and 7, Table 4). 


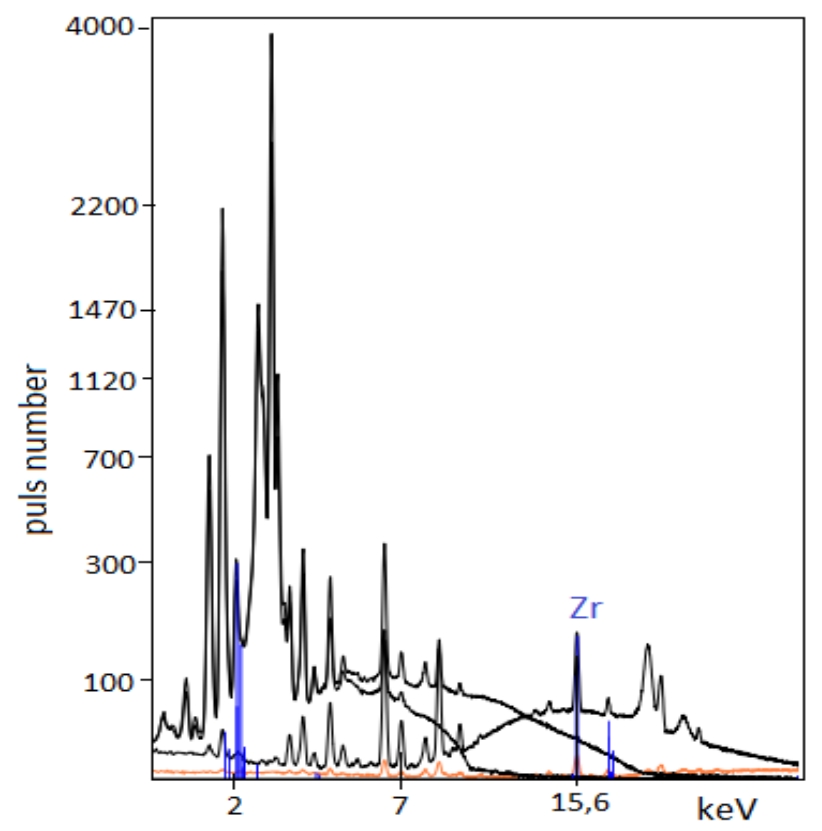

Figure 5. XRF spectrum of $\mathrm{NaX}$ with adsorbed zirconium on the surface.

Table 4. Relative content of oxides \% (wt.) in $\mathrm{NaX}$ structure after adsorption of $\mathrm{Zr}^{4+}$ and $\mathrm{Sr}^{2+}$ ions.

\begin{tabular}{l|l|l|l|l|l|l|l|l|l} 
\%(wt.) & $\mathrm{Na}_{2} \mathrm{O}$ & $\mathrm{MgO}$ & $\mathrm{Al}_{2} \mathrm{O}_{3}$ & $\mathrm{SiO}_{2}$ & $\mathrm{CaO}$ & $\mathrm{TiO}_{2}$ & $\mathrm{Fe}_{2} \mathrm{O}_{3}$ & $\mathrm{Zr}^{4+}$ & $\mathrm{Sr}^{2+}$ \\
\hline 1 & 55,7 & 13,5 & 11,2 & 10,7 & 1,05 & 0,374 & 0,319 & 0,28 & 0 \\
\hline 2 & 53,7 & $\mathbf{8 , 3 1}$ & $\mathbf{6 , 1 8}$ & 12,3 & 2,71 & 0,298 & 0,708 & $<0,1$ & 2,17
\end{tabular}

1. After zirconium adsorption; 2.-After strontium adsorption.
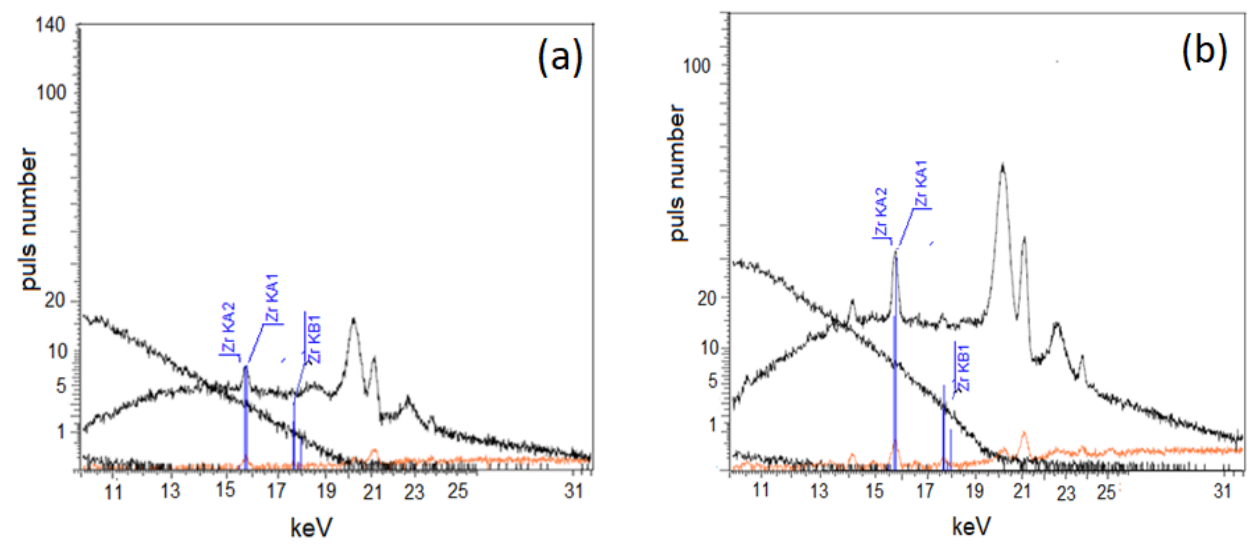

Figure 6. Part of XRF spectrum of $\mathrm{NaX}$ after desorption of zirconium ions: (a) by $10 \% \mathrm{HNO}_{3}$; (b) by $10 \mathrm{ml} 1 \%$ oxalic acid.
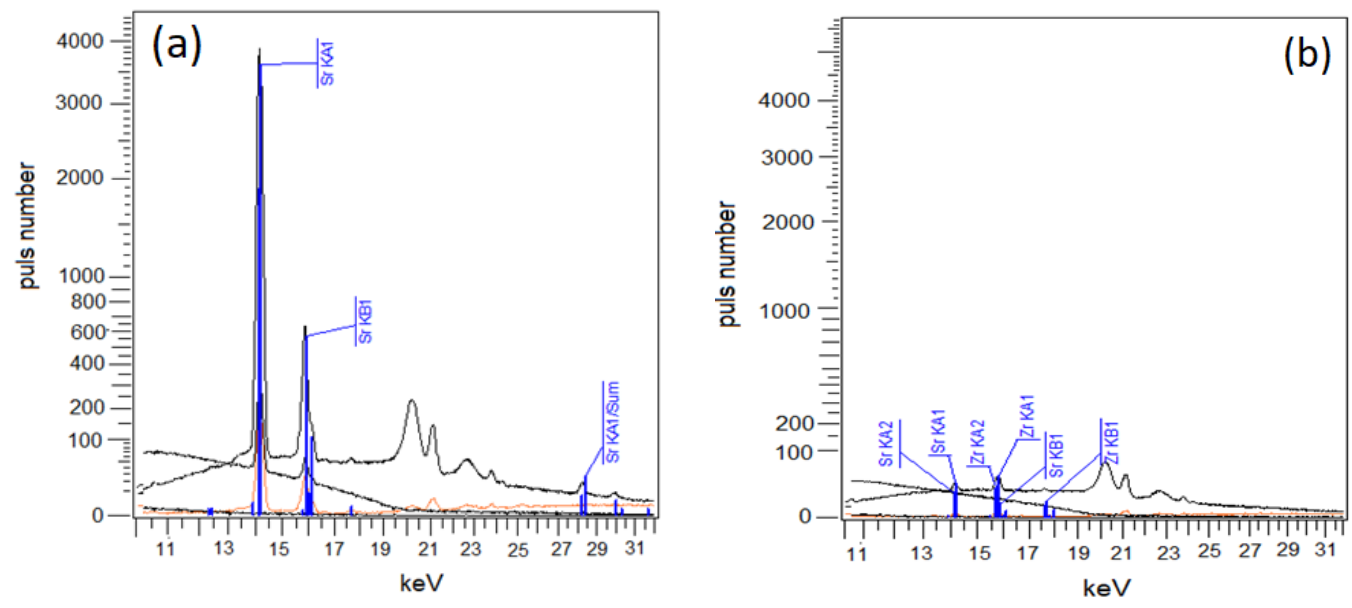

Figure 7. (a) Part of XRF spectrum of NaX samples with adsorbed strontium on the surface; (b) Part of XRF spectrum of $\mathrm{NaX}$ samples after 5 min of interaction with $10 \% \mathrm{HNO}_{3}$. 
Figures 6 (a) and (b) show the nitric and oxalic acids' effectiveness in terms of zirconium desorption from the zeolite surface. $80 \%$ of the total amount of adsorbed zirconium

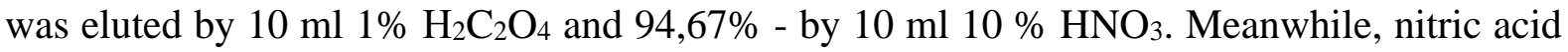
dilutes some elements of the zeolite structure together with zirconium.

Partial dissolution of $\mathrm{NaX}$ in nitric acid is described in Table 5.

Table 5. The changes of relative content $\%(w t$.) of oxides in zeolite's structure under dissolution in nitric acid ( $t$, min - duration of the interaction of $\mathrm{NaX}$ with concentrate $\mathrm{HNO}_{3}$ ).

\begin{tabular}{c|c|c|c|c|c|c|c}
$\begin{array}{c}\text { \% (wt.)/ } \\
\mathbf{T}, \text { min }\end{array}$ & $\mathbf{N a}_{2} \mathbf{O}$ & $\mathbf{M g O}$ & $\mathbf{A l}_{2} \mathbf{O}_{3}$ & $\mathbf{S i O}_{2}$ & $\mathbf{C a O}$ & $\mathbf{T i O}_{2}$ & $\mathbf{F e}_{2} \mathbf{O}_{3}$ \\
\hline 0 & 53,7 & 8,31 & 11,2 & 12,3 & 2,71 & 0,298 & 0,708 \\
\hline 15 & 38,4 & 5,83 & 12,8 & 31,3 & 0,818 & 1,34 & 0,658 \\
\hline 30 & 34,5 & 5,99 & 6,96 & 41,9 & 0,733 & 1,2 & 0,526 \\
\hline 215 & 19,9 & 3,31 & 4,93 & 63,3 & 0,486 & 1,69 & 0,592 \\
\hline 1440 & 23,5 & 0 & 2,66 & 63 & 0,66 & 2,27 & 0,724
\end{tabular}

The proportion of the $\mathrm{SiO}_{2}, \mathrm{TiO}_{2}$, and $\mathrm{Fe}_{2} \mathrm{O}_{3}$ oxides insoluble in nitric acid increases, the $\mathrm{Al}_{2} \mathrm{O}_{3}$ fraction decreases, and $\mathrm{MgO}$ is thoroughly washed out from the adsorbent matrix, as $\mathrm{NaX}$ zeolite degrades in concentrated $\mathrm{HNO}_{3}$ (Table 5). Together with zirconium cations, $\mathrm{Mg}^{2+}$, $\mathrm{Al}^{3+,}$ and $\mathrm{Na}^{+}$cations are recovered from the zeolite structure. Point of zero charges of $\mathrm{NaX}$ surface $\left(\mathrm{pH}_{\mathrm{pzc}}\right)$ is shifting from $\mathrm{pH}=11,5$ to $\mathrm{pH}=2,3$ after degradation $\mathrm{NaX}$ in acid medium, which lead to a decrease of zirconium adsorption. The decrease in zirconium adsorption may also be induced by the decrease in the number of sodium cations, some of which were exchangeable cations and were responsible for cation-exchange properties [38].

It is well known that the structure of faujasite is built of silicon layers $\left(\mathrm{Si}_{2} \mathrm{O}_{5}\right)$ attached to similar aluminum hydroxide layers $\left(\mathrm{Al}(\mathrm{OH})_{4}\right)$, called Gibbsite layers by relatively weak bonds. Sometimes, zeolite works as a molecular sieve. Faujasite possesses super cages with a diameter near 10-13 $\AA$. Their basic building block consists of a Si or Al atom in the tetrahedron center. This tetrahedron has oxygen in the four corners. Strontium, as a divalent cation, enters the inner sphere of zeolite [39-42] (Figure 8). This explains increased strontium adsorption by $\mathrm{NaX}$. In contrast with strontium, the hydrated zirconium ions are very large in size [41, 42] and do not penetrate the inner $\mathrm{NaX}$ sphere. Under normal conditions, zirconium ions are adsorbed only by zeolite's surface in a neutral medium. When zirconium results from $\beta^{-}$decay of radioactive ${ }^{90} \mathrm{Sr}$, or ${ }^{92} \mathrm{Sr}$ adsorbed by $\mathrm{NaX}$ (Figure 8 ), its interaction with $\mathrm{NaX}$ depends on the previous interaction of ${ }^{92} \mathrm{Sr}$ with the zeolite.

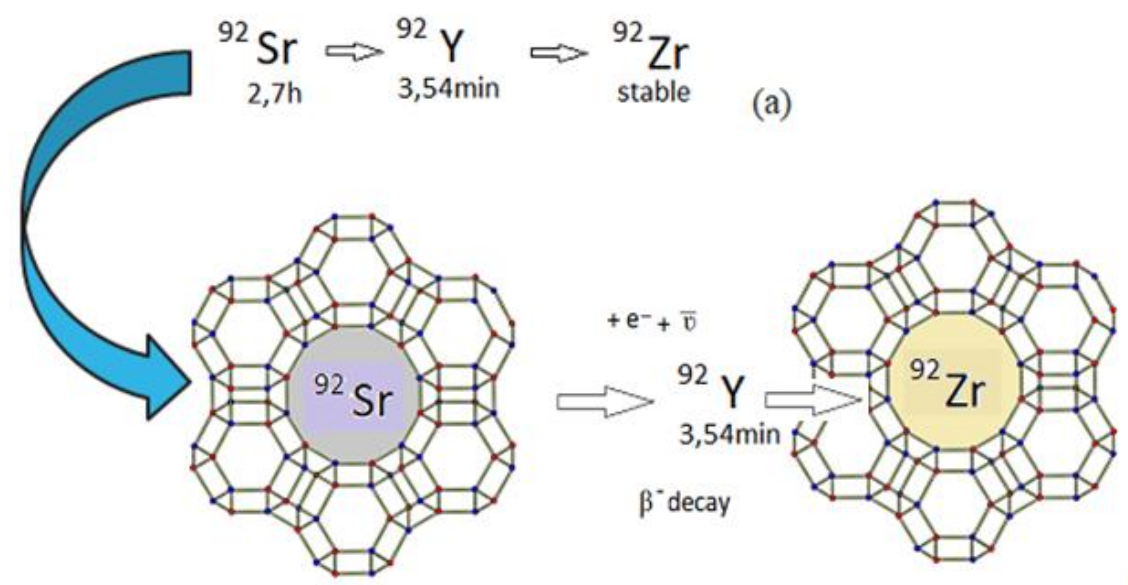

(b)

Figure 8. (a) Part of $\beta$-decay chain of radionuclides with $\mathrm{Ar}=92$; (b) strontium interaction with $\mathrm{NaX}$. A schematic image of a zeolite supercage was build according to the literature [43]. 
If ${ }^{92} \mathrm{Zr}$ results from ${ }^{92} \mathrm{Sr} \beta$ - decay, it remains in the inner zeolite sphere. However, like strontium, it will be easily desorbed by concentrated $\mathrm{HNO}_{3}$ since the acid destroys the zeolite itself.

\section{Conclusions}

The equilibrium in adsorption of zirconium ions by zeolite $\mathrm{NaX}$ establishes after 100 minutes of contact between zeolite surface and zirconium ions. Zirconium adsorption by zeolite $\mathrm{NaX}$ grows in the range of zirconium equilibrium concentrations of $27-3000 \mathrm{mg} / \mathrm{L}$. The maximum experimental adsorption values of $\mathrm{NaX}$ toward zirconium and strontium cations are $75 \mathrm{mg} \cdot \mathrm{g}^{-1}$ and $156 \mathrm{mg} \cdot \mathrm{g}^{-1}$, respectively. The process of zirconium adsorption is well described by the Freundlich adsorption theory, while strontium adsorption is well described by Langmuir adsorption theory.

Zeolite $\mathrm{NaX}$ becomes chemically unstable at $\mathrm{pH}$ less than 4 . The proportion of the $\mathrm{SiO}_{2}$, $\mathrm{TiO}_{2}$, and $\mathrm{Fe}_{2} \mathrm{O}_{3}$ oxides insoluble in nitric acid increases, the $\mathrm{Al}_{2} \mathrm{O}_{3}$ fraction decreases, and $\mathrm{MgO}$ is wholly removed from the adsorbent matrix, with the degradation of $\mathrm{NaX}$ in concentrated $\mathrm{HNO}_{3}$. The adsorbed radionuclides can be desorbed and re-released into the environment in an acid medium. If we suppose to use zeolite $\mathrm{NaX}$ as a carrier for radionuclides, special attention should be paid to this.

\section{Funding}

This work was supported by a research grant in Nuclear Forensics STCU [project 9906].

\section{Acknowledgments}

The authors are grateful to the librarians of Uzhgorod National University (Kyryliuk Nataly, Dankanych Oksana and Kobyliatskiy V.) for their help in working on this publication. The authors are also grateful to Myslin Mariana to determine the point of zero charges of the zeolite surface.

\section{Conflicts of Interest}

The authors declare that they have no known competing financial interests or personal relationships that could have influenced the work reported in this paper.

\section{References}

1. Barrer, R.M.; Meier, W.M. Structural and ion sieve properties of a synthetic crystalline exchanger. Trans. Faraday Society 1958, 54, 1074-1085, https://doi.org/10.1039/TF9585401074.

2. Zhang, X.; Tang, D.; Zhang, M.; Yang, R. Synthesis of NaX zeolite: Influence of crystallization time, temperature and batch molar ratio $\mathrm{SiO} 2 / \mathrm{Al} 2 \mathrm{O} 3$ on the particulate properties of zeolite crystals. Powder Technol. 2013, 235, 322-328, https://doi.org/10.1016/j.powtec.2012.10.046.

3. Fang, X.-H.; Fang, F.; Lu, C.-H.; Zheng, L. Removal of Cs+, Sr2+, and Co2+ Ions from the Mixture of Organics and Suspended Solids Aqueous Solutions by Zeolites. Nuclear Engineering and Technology 2017, 49, 556-561, https://doi.org/10.1016/j.net.2016.11.008.

4. Ovhal, S.; Butler, I.; Xu, S. The Potential of Zeolites to Block the Uptake of Radioactive Strontium-90 in Organisms. Contemporary Chemistry 2018, 1 .

5. Matsuda, M. Application 25 - Zeolite Membrane. In Nanoparticle Technology Handbook (Third Edition), Naito, M., Yokoyama, T., Hosokawa, K., Nogi, K., Eds. Elsevier: 2018, 539-542, https://doi.org/10.1016/B978-0-444-64110-6.00032-9. 
6. Jia, G.; Magro, L.; Torri, G.; Mariani, S. Sensitive and accurate methods for determination of low activity level of $90 \mathrm{Sr}$ and $137 \mathrm{Cs}$ in grass/vegetable samples. Appl. Radiat. Isot. 2021, 169, 109547, https://doi.org/10.1016/j.apradiso.2020.109547.

7. Vasylyeva, H.V., Mironyuk, I.F., Mykytyn, I.M. Adsorption of $\mathrm{Co}^{2+}$ and radioactive ${ }^{60} \mathrm{Co}$ by mesoporous $\mathrm{TiO}_{2}$. Chemistry, physics and technology of surface. 2019, 10, 446-457, https://www.doi.org/10.15407/hftp10.04.446.

8. Mironyuk, I., Tatarchuk, T., Vasylyeva, H., Naushad, M., Mykytyn, I. Adsorption of Sr(II) cations onto phosphated mesoporous titanium dioxide: Mechanism, isotherm and kinetics studies. Journal of Environmental Chemical Engineering 2019, 7, 103430, https://www.doi.org/10.1016/j.jece.2019.103430.

9. Mironyuk, I., Tatarchuk, T., Naushad, M., Vasylyeva, H., Mykytyn, I. Highly efficient adsorption of strontium ions by carbonated mesoporous TiO2. J. Mol. Liq. 2019, 285, 742-753, https://www.doi.org/10.1016/j.molliq.2019.04.111.

10. Kylivnik Yu. M., Tryshyn V. V., Strilchuk M.V., Gaidar O.V., Vasylieva H.V., Vuchkan, S.I., Sych O.Ya., Syika, I.Yu. The titanium silicate influence on the $\mathrm{Zn}$ (II) and $\mathrm{Sr}$ (II) migration in the aquatic environment. Nucl. Phys. At. Energy, 2020, 21, 249-255, https://doi.org/10.15407/jnpae2020.03.249.

11. Abdel-Galil, E.A.; Hassan, R.S.; Eid, M.A. Assessment of nano-sized stannic silicomolybdate for the removal of $137 \mathrm{Cs}, 90 \mathrm{Sr}$, and $141 \mathrm{Ce}$ radionuclides from radioactive waste solutions. Appl. Radiat. Isot. 2019, 148, 91101, https://doi.org/10.1016/j.apradiso.2019.03.029.

12. Mironyuk, I.F.; Gun'ko, V.M.; Vasylyeva, H.V.; Goncharuk, O.V.; Tatarchuk, T.R.; Mandzyuk, V.I.; Bezruka, N.A.; Dmytrotsa, T.V. Effects of enhanced clusterization of water at a surface of partially silylated nanosilica on adsorption of cations and anions from aqueous media. Microporous Mesoporous Mater. 2019, 277, 95-104, https://doi.org/10.1016/j.micromeso.2018.10.016.

13. Mironyuk, I.F.; Mykytyn, I.M.; Kaglyan, O.Ye.; Gudkov, D.I.; Vasylyeva, H.V. ${ }^{90} \mathrm{Sr}$ adsorption from the aquatic environment of Chornobyl exclusion zone by chemically enhanced $\mathrm{TiO}_{2}$. Nucl. Phys. At. Energy, 2020, 21, 4, 347-353, https://doi.org/10.15407/jnpae2020.04.347.

14. Soltys, L.; Myronyuk, I.; Tatarchuk, T.; Tsinurchyn, V. Zeolite-based Composites as Slow Release Fertilizers (Review). Physics and Chemistry of Solid State 2020, 21, 89-104, https://www.doi.org/10.15330/pcss.21.1.89-104.

15. Takata, T.; Tsunoji, N.; Takamitsu, Y.; Sadakane, M.; Sano, T. Incorporation of various heterometal atoms in CHA zeolites by hydrothermal conversion of FAU zeolite and their performance for selective catalytic reduction of NOx with ammonia. Microporous Mesoporous Mater. 2017, 246, 89-101, https://doi.org/10.1016/j.micromeso.2017.03.018.

16. Ezzeddine, Z.; Batonneau-Gener, I.; Pouilloux, Y.; Hamad, H.; Saad, Z. Synthetic Nax Zeolite as a Very Efficient Heavy Metals Sorbent in Batch and Dynamic Conditions. Colloids and Interfaces 2018, 2, https://www.doi:10.3390/colloids2020022.

17. Korkuna, O.; Leboda, R.; Skubiszewska-Zie, ba, J.; Vrublevs'ka, T.; Gun'ko, V.M.; Ryczkowski, J. Structural and physicochemical properties of natural zeolites: clinoptilolite and mordenite. Microporous Mesoporous Mater. 2006, 87, 243-254, https://doi.org/10.1016/j.micromeso.2005.08.002.

18. Król, M. Natural vs. Synthetic Zeolites. Crystals 2020, 10, https://doi.org/10.3390/cryst10070622.

19. Levenets, V.V.; Lonin, A.Y.; Omelnik, O.P.; Shchur, A.O. Comparison the sorption properties of clinoptilolite and synthetic zeolite during sorption strontium from the water solutions in static conditions: Sorption and quantitative determination of strontium by the method PIXE. Journal of Environmental Chemical Engineering 2016, 4, 3961-3966, https://www.doi.org/10.1016/j.jece.2016.09.011.

20. Elboughdiri, $\mathrm{N}$. The use of natural zeolite to remove heavy metals $\mathrm{Cu}$ (II), $\mathrm{Pb}$ (II) and Cd (II), from industrial wastewater. Cogent Engineering 2020, 7, 1782623, https://doi.org/10.1080/23311916.2020.1782623.

21. Esmaeili, A.; Mobini, M.; Eslami, H. Removal of heavy metals from acid mine drainage by native natural clay minerals, batch and continuous studies. Applied Water Science 2019, 9, 97, https://doi.org/10.1007/s13201-019-0977-x.

22. Taamneh, Y.; Sharadqah, S. The removal of heavy metals from aqueous solution using natural Jordanian zeolite. Applied Water Science 2017, 7, 2021-2028, https://doi.org/10.1007/s13201-016-0382-7.

23. Zolfonoun, E.; Monji, A.B.; Taghizadeh, M.; Ahmadi, S.J. Selective and direct sorption of zirconium from acidic leach liquor of zircon concentrate by rice bran. Miner. Eng. 2010, 23, 755-756, https://doi.org/10.1016/j.mineng.2010.05.005.

24. O’Hara, M.J.; Murray, N.J.; Carter, J.C.; Kellogg, C.M.; Link, J.M. Tandem column isolation of zirconium89 from cyclotron bombarded yttrium targets using an automated fluidic platform: Anion exchange to 
hydroxamate resin columns. J. $\quad$ Chromatogr. $\quad \mathbf{2 0 1 8 ,} \quad 1567, \quad 37-46$, https://doi.org/10.1016/j.chroma.2018.06.035.

25. O’Hara, M.J.; Murray, N.J.; Carter, J.C.; Kellogg, C.M.; Link, J.M. Hydroxamate column-based purification of zirconium-89 (89Zr) using an automated fluidic platform. Appl. Radiat. Isot. 2018, 132, 85-94, https://doi.org/10.1016/j.apradiso.2017.10.048.

26. Bhatt, N.B.; Pandya, D.N.; Wadas, T.J. Recent Advances in Zirconium-89 Chelator Development. Molecules 2018, 23, http://dx.doi.org/10.3390/molecules23030638.

27. Akolekar, D.; Chaffee, A.; Howe, R.F. The transformation of kaolin to low-silica X zeolite. Zeolites 1997, 19, 359-365, https://www.doi.org/10.1016/S0144-2449(97)00132-2.

28. Bondareva, G.V.; Rat'ko, A.I.; Azarov, S.M. Hydrothermal Synthesis of Zeolite NaX on Porous Ceramic Supports. Inorg. Mater. 2003, 39, 605-609, https://www.doi.org/10.1023/A:1024053304236.

29. Hamilton, K.E.; Coker, E.N.; Sacco, A.; Dixon, A.G.; Thompson, R.W. The effects of the silica source on the crystallization of zeolite NaX. Zeolites 1993, 13, 645-653, https://doi.org/10.1016/0144-2449(93)90137R.

30. Sadeghbeigi, R. Chapter 4 - FCC Catalysts. In Fluid Catalytic Cracking Handbook (Third Edition), Sadeghbeigi, R., Ed. Butterworth-Heinemann: Oxford, 2012; https://doi.org/10.1016/C.2010-0-67291-9.

31. Hartman, R.L.; Fogler, H.S. Understanding the Dissolution of Zeolites. Langmuir 2007, 23, 5477-5484, https://www.doi.org/10.1021/la063699g.

32. Mironyuk, I.; Tatarchuk, T.; Vasylyeva, H.; Gun'ko, V.M.; Mykytyn, I. Effects of chemosorbed arsenate groups on the mesoporous titania morphology and enhanced adsorption properties towards $\operatorname{Sr}(\mathrm{II})$ cations. $J$. Mol. Liq. 2019, 282, 587-597, https://doi:10.1016/J.MOLLIQ.2019.03.026.

33. Vasylyeva, H.; Mironyuk, I.; Mykytyn, I.; Savka, K. Equilibrium studies of yttrium adsorption from aqueous solutions by titanium dioxide. Appl. Radiat. Isot. 2021, 168, 109473, https://doi.org/10.1016/j.apradiso.2020.109473.

34. Tran, H.N.; You, S.-J.; Hosseini-Bandegharaei, A.; Chao, H.-P. Mistakes and inconsistencies regarding adsorption of contaminants from aqueous solutions: A critical review. Water Res. 2017, 120, 88-116, https://doi.org/10.1016/j.watres.2017.04.014.

35. Tran, H.N.; Tomul, F.; Thi Hoang Ha, N.; Nguyen, D.T.; Lima, E.C.; Le, G.T.; Chang, C.-T.; Masindi, V.; Woo, S.H. Innovative spherical biochar for pharmaceutical removal from water: Insight into adsorption mechanism. J. Hazard. Mater. 2020, 394, 122255, https://www.doi.org/10.1016/j.jhazmat.2020.122255.

36. Standard Deviation Calculator. Available online: http://www.calculator.net/standard-deviationcalculator.html

37. Deri, M.-A. Zirconium-89: Radiochemistry and Ligand Development toward Improved PET Applications. A dissertation submitted to the Graduate Faculty in Chemistry in partial fulfillment of the requirements for the degree of Doctor of Philosophy,Graduate Center, City University of New York, 2015.

38. Mironyuk, I.; Mykytyn, I.; Vasylyeva, H.; Savka, K. Sodium-modified mesoporous TiO2: Sol-gel synthesis, characterization and adsorption activity toward heavy metal cations. J. Mol. Liq. 2020, 316, 113840, https://www.doi.org/10.1016/j.molliq.2020.113840.

39. Munthali, M.W.; Johan, E.; Aono, H.; Matsue, N. Cs+ and Sr2+ adsorption selectivity of zeolites in relation to radioactive decontamination. Journal of Asian Ceramic Societies 2015, 3, 245-250, https://www.doi.org/10.1016/j.jascer.2015.04.002.

40. Mimura, H.; Kanno, T. Distribution and Fixation of Cesium and Strontium in Zeolite A and Chabazite. $J$. Nucl. Sci. Technol. 1985, 22, 284-291, https://www.doi.org/10.1080/18811248.1985.9735658.

41. Martínez, C.; Corma, A. 5.05 - Zeolites. In Comprehensive Inorganic Chemistry II (Second Edition), Reedijk, J., Poeppelmeier, K., Eds. Elsevier: Amsterdam, 2013; 103-131, https://doi.org/10.1016/B978-0-08-0977744.00506-4.

42. Busca, G. Chapter 7 - Zeolites and Other Structurally Microporous Solids as Acid-Base Materials. In Heterogeneous Catalytic Materials, Busca, G., Ed. Elsevier: Amsterdam, 2014; 197-249, https://doi.org/10.1016/B978-0-444-59524-9.00007-9.

43. Feng, R.; Yan, X.; Hu, X.; Qiao, K.; Yan, Z.; Rood, M.J. High performance of H3BO3 modified USY and equilibrium catalyst with tailored acid sites in catalytic cracking. Microporous Mesoporous Mater. 2017, 243, 319-330, https://doi.org/10.1016/j.micromeso.2017.02.041. 